This document is confidential and is proprietary to the American Chemical Society and its authors. Do not copy or disclose without written permission. If you have received this item in error, notify the sender and delete all copies.

\title{
Paramagnetic Molecular Grippers: The Elements of Six-State Redox Switches
}

\begin{tabular}{|c|c|}
\hline Journal: & The Journal of Physical Chemistry Letters \\
\hline Manuscript ID & jz-2016-01094x.R1 \\
\hline Manuscript Type: & Letter \\
\hline Date Submitted by the Author: & $11-J u n-2016$ \\
\hline Complete List of Authors: & $\begin{array}{l}\text { Milic, Jovana; ETH Zürich, Laboratorium für Organische Chemie } \\
\text { Zalibera, Michal; Max-Planck-Institut fur chemische Energiekonversion; } \\
\text { Slovenska Technicka Univerzita Ustav fyzikalnej chemie a chemickej fyziky, } \\
\text { Institute of Physical Chemistry and Chemical Physics } \\
\text { Pochorovski, Igor; ETH Zurich, Laboratorium für Organische Chemie } \\
\text { Trapp, Nils; ETH Zurich, Laboratorium fur Organische Chemie } \\
\text { Nomrowski, Julia; University of Basel, Department of Chemistry } \\
\text { Neshchadin, Dmytro; Graz University of Technology, Institute of Physical } \\
\text { and Theoretical Chemistry } \\
\text { Ruhlmann, Laurent; Université de Strasbourg, Institut de Chimie } \\
\text { Boudon, Corinne; Université de Strasbourg, Institut de Chimie } \\
\text { Wenger, Oliver; University of Basel, Department of Chemistry } \\
\text { Savitsky, Anton; Max-Planck-Institut fur chemische Energiekonversion } \\
\text { Lubitz, Wolfgang; Max-Planck-Institut fuer Chemische Energiekonversion, } \\
\text { Gescheidt, Georg; Graz University of Technology, Institute of Physical and } \\
\text { Theoretical Chemistry } \\
\text { Diederich, François; ETH Zurich, Laboratorium fur Organische Chemie }\end{array}$ \\
\hline
\end{tabular}




\section{Paramagnetic Molecular Grippers: The Elements of Six-State Redox Switches}

Jovana Milić ${ }^{1}$, Michal Zalibera, ${ }^{2,3}$, Igor Pochorovski ${ }^{1}$, Nils Trapp $^{1}$, Julia Nomrowski ${ }^{4}$, Dmytro Neshchadin ${ }^{5}$, Laurent Ruhlmann $^{6}$, Corinne Boudon $^{6}$, Oliver S. Wenger ${ }^{4}$, Anton Savitsky ${ }^{2}$, Wolfgang Lubitz ${ }^{2}$, Georg Gescheidt ${ }^{5}$, François Diederich ${ }^{{ }^{*}}$

${ }^{1}$ Laboratory of Organic Chemistry, ETH Zurich, Vladimir-Prelog-Weg 3, 8093 Zurich, Switzerland

${ }^{2}$ Max Planck Institute for Chemical Energy Conversion, Stiftstrasse 34-36, 45470 Mülheim an der Ruhr, Germany

${ }^{3}$ Institute of Physical Chemistry and Chemical Physics, FCHPT STU, Radlinského 9, 81237 Bratislava, Slovakia

${ }^{4}$ University of Basel, St. Johanns-Ring 19, 4056 Basel, Switzerland

${ }^{5}$ Institute of Physical and Theoretical Chemistry, NAWI Graz, Graz University of Technology, Stremayrgasse 9/Z2, 8010 Graz, Austria

${ }^{6}$ Université de Strasbourg, Laboratoire d'Électrochimie et Chimie Physique du Corps Solide, Institut de Chimie de Strasbourg, 4 rue Blaise Pascal, CS 90032, 67081 Strasbourg, France

\section{AUTHOR INFORMATION}




\title{
Corresponding Author
}

*diederich@org.chem.ethz.ch

\begin{abstract}
The development of semiquinone-based resorcin[4]arene cavitands expands the toolbox of switchable molecular grippers by introducing the first paramagnetic representatives. The semiquinone (SQ) states were generated electrochemically, chemically, and photochemically. We analyzed their electronic, conformational, and binding properties by cyclic voltammetry, UV/Vis spectroelectrochemistry, EPR and transient absorption spectroscopy, in conjunction with DFT calculations. The utility of UV/Vis spectroelectrochemistry and EPR spectroscopy in evaluating the conformational features of resorcin[4]arene cavitands is demonstrated. Guest binding properties were found to be enhanced in the SQ state as compared to the quinone $(\mathrm{Q})$ or the hydroquinone (HQ) states of the cavitands. Thus, these paramagnetic SQ intermediates open the way to six-state redox switches provided by two conformations (open and closed) in three redox states (Q, SQ, and HQ) possessing distinct binding ability. The switchable magnetic properties of these molecular grippers and their responsiveness to electrical stimuli has the potential for development of efficient molecular devices.
\end{abstract}

\section{TOC GRAPHICS}

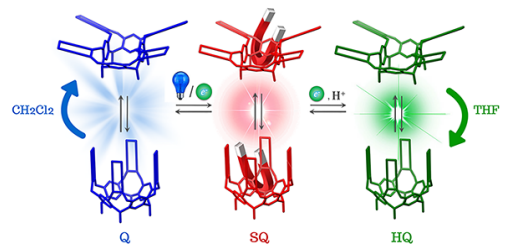

KEYWORDS supramolecular chemistry, photoredox switch, host-guest chemistry, semiquinones, cavitands, molecular grippers. 
Nanodevices that are able to perform controlled motion, ${ }^{1-3}$ such as molecular grippers, ${ }^{4-6}$ are of particular interest due to their ability to expand and contract in response to external stimuli. This behavior renders them promising for applications as transporters, ${ }^{7,8}$ sensors, ${ }^{9-15}$ nanoreactors,$^{14,16-21}$ or elements in nanorobotics. ${ }^{4,7,8,22,23}$ Resorcin[4]arenes are suitable platforms for the development of molecular grippers, owing to their capability to adopt bistable, open (kite) and closed (vase) conformations. ${ }^{4,24,25}$ The vase-kite equilibrium can be influenced by various stimuli, such as solvent choice, ${ }^{26,27}$ temperature, ${ }^{28} \mathrm{pH}^{, 2}{ }^{29}$ metal-ion concentration, ${ }^{30}$ or redox processes..$^{24,25,31}$ The development of cavitands that can respond to electrical or electromagnetic stimuli is required for future applications of resorcin[4]arene-based molecular grippers. ${ }^{24}$ This prerequisite imposes demand for novel methodologies to design and study conformational and binding properties, which until now were mainly investigated by $\mathrm{NMR}^{32}$ or UV/Vis spectroscopy. ${ }^{29}$ The usage of electric potential or light ${ }^{20,33}$ to trigger the switching of resorcine[4]arene-based molecular grippers, however, remains largely unexplored, despite their capacity to act as multi-state switches that can be of great interest in the design of various molecular devices, such as logic gates, sensors, actuators, and pumps. ${ }^{34-40}$

Herein, we report electronic, conformational, and binding properties of the quinone-based resorcin[4]arene cavitands $\mathbf{1}$ and $\mathbf{2}$ in their semiquinone (SQ) redox states. While their quinone (Q) and hydroquinone (HQ) states (Figure 1, blue and green) have already been investigated, ${ }^{31}$ the generation and investigation of the SQ states (Figure 1, red) remained a challenge. Access to the SQ intermediates could pave the way towards cavitands with properties that can be controlled by voltage or light. A system that can be reversibly interconverted between its $\mathbf{Q}, \mathbf{S Q}$, or $\mathbf{H Q}$ states and exhibits two different conformations (vase or kite) with distinctive binding properties, would represent a rare example of a six-state redox switch. ${ }^{38}$ 
We report the generation of the SQ radical anions of cavitands $\mathbf{1}$ and $\mathbf{2}$ (i) electrochemically by cyclic voltammetry, (ii) chemically by reduction with $\mathrm{CoCp}_{2}$, and (iii) photochemically using photoreduction with a catalytic amount of $\left[\mathrm{Ru}(\mathrm{bpy})_{3}\right]^{2+}$ as a photoreductant and $\mathrm{Et}_{3} \mathrm{~N}$ as a sacrificial electron donor, and describe their electronic, conformational, and binding properties. Model compounds 3-5, representing individual cavitand walls, were also investigated (for their synthesis, see Section S1, Supporting Information).

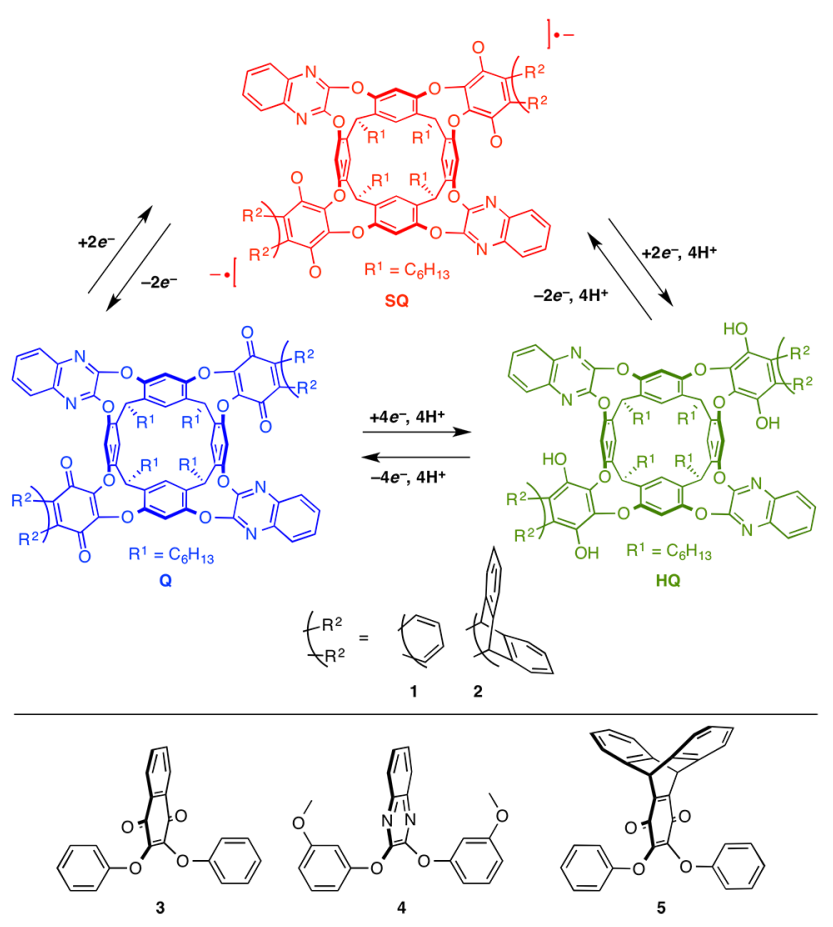

Figure 1. Top: Redox interconversion of cavitand systems 1-2. Bottom: Model compounds 3-5 employed in this study.

In the electrochemical study, we used cyclic voltammetry $(\mathrm{CV})$ to generate and investigate the SQ state of cavitands 1-2. The analysis of the voltammograms in $\mathrm{CH}_{2} \mathrm{Cl}_{2}$ revealed a three-step reduction of both cavitands, with reduction potentials of $-1.10 \mathrm{~V},-1.62 \mathrm{~V}$, and $-2.19 \mathrm{~V}$ $\left(E_{1 / 2}\right.$ values versus $\mathrm{Fc}^{+} / \mathrm{Fc}$ as an internal potential reference, $E_{1 / 2}\left(\mathrm{Fc}^{+} / \mathrm{Fc}\right)=0.66 \mathrm{~V}$ vs. $\left.\mathrm{NHE}\right)$ for cavitand $\mathbf{1}$, and $-0.88 \mathrm{~V},-1.55 \mathrm{~V}$, and $-2.22 \mathrm{~V}$ for cavitand $\mathbf{2}$, respectively (Figure 2a-b). 
Rotating disc voltammetry (RDV) showed that each reduction step occurs as a two-electron process with the first step being fully reversible (for details, see Section S4, Supporting Information). This reversible two-electron process can in principle result in the formation of two different semiquinone species (Figure 2d): a diamagnetic bis-SQ dianion in the singlet spin state $\boldsymbol{S}(S=0)$ or a paramagnetic bis-SQ dianion in the triplet spin state $\boldsymbol{T}(S=1)$. DFT calculations at the B3LYP/6-31G(d) level of theory indicate that the bis-SQ dianion in the triplet spin state is favored for doubly reduced cavitands 1-2 (for details, see Section S9, Supporting Information).
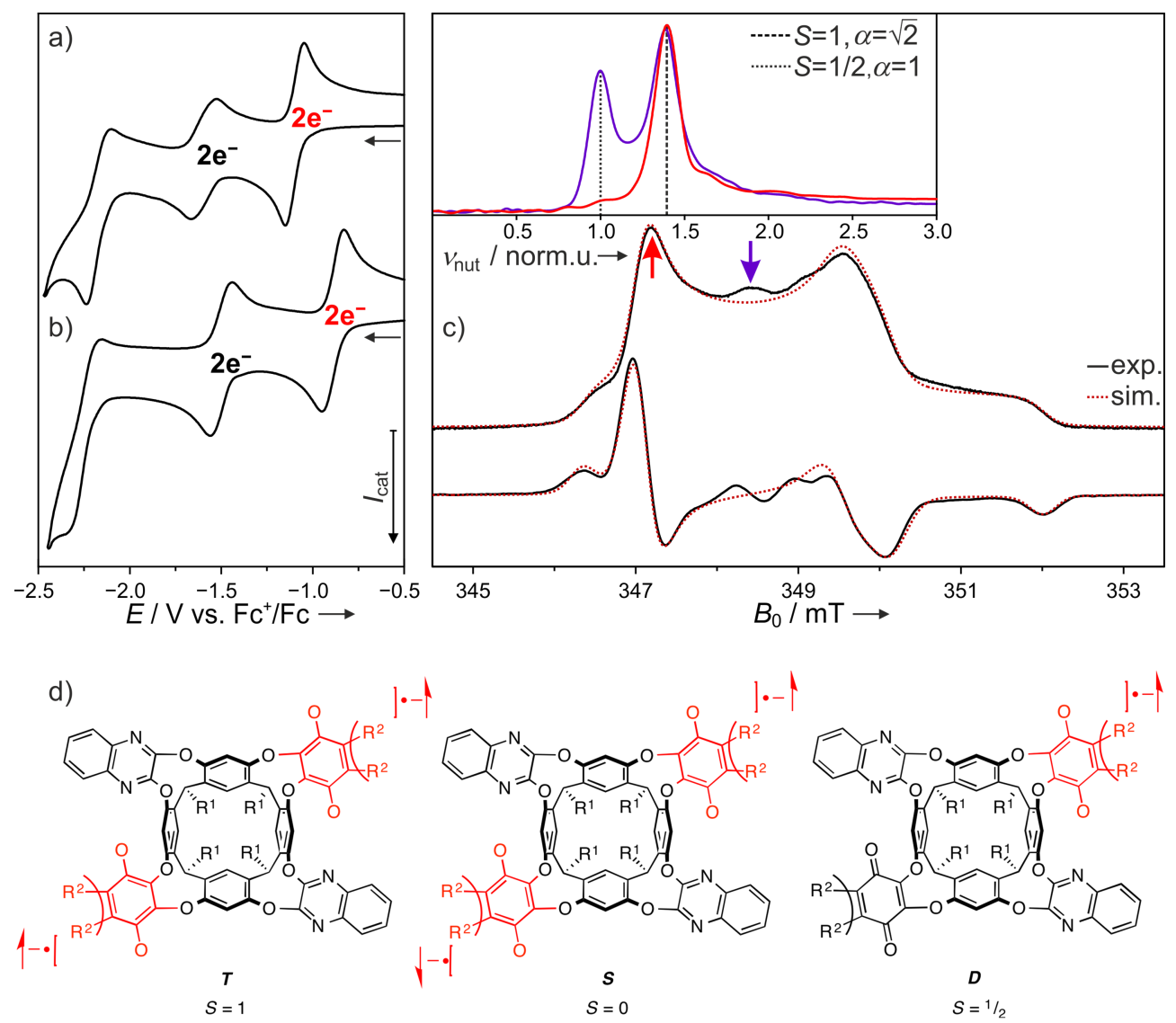

Figure 2. Cyclic voltammograms of cavitands (a) 1 and (b) 2 (0.5 mM) recorded in $n-\mathrm{Bu}_{4} \mathrm{NBF}_{4} / \mathrm{CH}_{2} \mathrm{Cl}_{2} \quad(0.1 \mathrm{M})$ at ambient temperature using a standard three-electrode electrochemical cell with glassy carbon working electrode at a scan rate of $100 \mathrm{mVs}^{-1}$. Ferrocene $\left(\mathrm{Fc}^{+} / \mathrm{Fc}\right)$ was used as an internal potential reference. Both reduction waves are two- 
electron transfer processes (RDV, Section S4.2, Supporting Information). (c) Top, black line: ED EPR spectrum of reduced 2 in $\mathrm{CD}_{2} \mathrm{Cl}_{2}$ at $80 \mathrm{~K}$ obtained using the $t_{p}-\tau-2 t_{p}-\tau$-echo sequence with $t_{p}=24 \mathrm{~ns}$ and $\tau=150 \mathrm{~ns}$; bottom, black line: the corresponding first derivative spectrum. Red dotted lines show the simulations of the triplet bis-SQ-2 dianion spectrum using spin Hamiltonian parameters from Table 1. Inset shows electron spin nutation spectra (red and purple) obtained at field position marked by the arrows (color corresponds to the spin nutation spectra) in the ED-EPR spectrum. The ratio of the nutation frequencies $\left(v_{\text {nut }}\right)$ of 1.41 is in good agreement with $\sqrt{2}$, expected for $v_{\text {nut }}(S=1) / v_{\text {nut }}(S=1 / 2)$, confirming the presence of the triplet bis-SQ-2 dianion $\left(S=1\right.$, red) and a SQ-2 monoanion $\left(S=\frac{1}{2}\right.$; purple), a minor component that forms by disproportionation of the bis-SQ dianion species in solution. $.^{41-43} \mathrm{ED}=$ echo-detected; $\mathrm{CW}=$ continuous wave. (d) Potential semiquinone products resulting from the two-electron reduction of cavitands $\mathbf{1}-\mathbf{2}$ in the $\mathbf{Q}$ state: triplet bis-SQ $\boldsymbol{T}(S=1)$ and singlet bis-SQ $\boldsymbol{S}(S=0)$. The monoanion $\boldsymbol{D}(S=1 / 2)$ commonly forms by disproportionation of the bis-SQ dianion species in solution. ${ }^{41-43} \mathrm{R}^{1}, \mathrm{R}^{2}$ are defined in Figure 1.

The electronic state of the reduced species was further experimentally analyzed by pulsed EPR spectroscopy (for details, see Section S5, Supporting Information). ${ }^{44-46}$ The electron spin echo detected (ED) EPR spectrum of cavitand 2 reduced in $\mathrm{CD}_{2} \mathrm{Cl}_{2}$ by an excess of cobaltocene $\left(\mathrm{CoCp}_{2}\right)$ is shown in Figure 2c (black line). The EPR spectrum shows spectral contributions from two paramagnetic species. The dominant one exhibits a characteristic fine structure resulting from the dipole-dipole interaction of the two unpaired electron spins in the triplet spin state $\boldsymbol{T}(S=1)$ and is assigned to the bis-SQ-2 dianion (red arrow in Figure 2d). The signal of the minor paramagnetic species appears close to the center of the spectrum $\left(B_{0}=348.5 \mathrm{mT}\right.$, purple arrow in Figure 2c). This signal is ascribed to the SQ-2 monoanion in the doublet spin 
state $\boldsymbol{D}(S=1 / 2)$, which is typically formed by the disproportionation reactions of bis-SQ species in solution. ${ }^{41-43}$ The spectral contribution assigned to the bis-SQ-2 dianion can be well reproduced in a simulation (Figure 2c, red dotted line) using the spin Hamiltonian parameters summarized in Table 1. The analysis of the triplet bis-SQ-1 (see Section S5, Supporting Information) and bis-SQ-2 dianions reveals rhombic $g$ tensors with canonical values that agree well with those typically observed for semiquinone radicals, and rhombic Zero Field Splitting (ZFS) tensors with similar $D$ and $E$ parameters of $78 \mathrm{MHz}$ and $3 \mathrm{MHz}$, respectively. ${ }^{41,46-50}$

Table 1. Spin Hamiltonian parameters used to simulate the spectra of the triplet bis-SQ dianions

\begin{tabular}{|c|c|c|c|c|}
\hline & \multirow{2}{*}{$\begin{array}{l}g \text { factor } \\
g_{\mathrm{x}}, g_{\mathrm{y}}, g_{\mathrm{z}}^{\mathrm{a}}\end{array}$} & \multicolumn{2}{|c|}{ ZFS } & \multirow{2}{*}{$\begin{array}{l}\text { distance } \\
r / \AA^{c}\end{array}$} \\
\hline & & $D / \mathrm{MHz}^{\mathrm{b}}$ & $E / \mathrm{MHz}^{\mathrm{b}}$ & \\
\hline bis-SQ-1 $^{2-}$ & $2.0070,2.0052,2.0025$ & 77.8 & 3.1 & 10.0 \\
\hline bis-SQ-2 ${ }^{2-}$ & $2.0074,2.0056,2.0026$ & 78.1 & 3.1 & 10.0 \\
\hline
\end{tabular}

The spin state of a paramagnetic species under study can be additionally confirmed by the electron spin echo nutation experiment (see Section S5, Supporting Information, for details). ${ }^{44-46}$ Here, a preparation microwave pulse of variable duration is inserted in the pulse sequence before the Hahn echo detection (ED) block and the oscillation (nutation) of the echo signal is monitored as a function of the preparation pulse length. The frequency of the EPR signal oscillation with increasing preparation pulse length (nutation frequency, $v_{\text {nut }}$ ) is related to the spin quantum numbers $\left(S, \mathrm{~m}_{\mathrm{s}}\right)$ of the excited EPR transition according to the equation

$$
\omega_{\text {nut }}=2 \pi v_{\text {nut }}=\frac{2 \pi}{T_{\text {nut }}}=\alpha \cdot \omega_{1}, \quad \alpha=\sqrt{S(S+1)-m_{s}\left(m_{s} \pm 1\right)}
$$

where $\omega_{\text {nut }}$ is the corresponding nutation angular frequency and $T_{\text {nut }}$ its period, $\omega_{1}$ is the microwave field strength in angular frequency units, and the $\alpha$ factors describing the transitions 
in the $S=1 / 2$ and $S=1$ spin manifolds are $\alpha=1$ and $\alpha=\sqrt{2}$, respectively. The spin state of the species under study can thus be determined by comparing the nutation frequency $\left(v_{\text {nut }}\right)$ of the measured EPR signal with that of a reference with known spin state. ${ }^{44-46}$ The nutation spectra for the two signals present in the ED EPR spectrum of reduced cavitand $\mathbf{2}$ are shown as inset in Figure 2c. The nutation frequency of the dominant signal is $1.41(\sqrt{2})$ times higher than that observed for the minor signal, as expected for the triplet $\boldsymbol{T}(S=1)$ and the doublet $\boldsymbol{D}(S=1 / 2)$ species (Figure 2c). The results of the nutation experiments thus support the assignment of the dominant signal to the triplet bis-SQ-2 $(S=1)$ dianion and the minor signal to the monoanionic SQ-2 species $(S=1 / 2){ }^{41-43}$ Comparable EPR spectra with the same assignments were obtained for cavitand 1 (for details, see Section S5, Supporting Information). Thus, the EPR experiments verified the formation of the paramagnetic bis-SQ species in the triplet spin state upon twoelectron reduction of the cavitands $\mathbf{1}-\mathbf{2}$.

Thereafter, our goal was to achieve the photochemical generation of triplet bis-SQ dianion states, which could pave the way for the development of photoredox-switchable molecular grippers. First, we tested the photoreduction conditions on compounds $\mathbf{3}$ and $\mathbf{5}$ (Figure 1), which represent models for individual quinone cavitand walls and require one-electron transfer for the formation of the $\mathbf{S Q}$ state. Photoreduction was performed in $\mathrm{CH}_{2} \mathrm{Cl}_{2}$ via excitation of catalytic amounts $(0.1 \mathrm{~mol} \%)$ of $\left[\mathrm{Ru}(\mathrm{bpy})_{3}\right]^{2+}$ in the presence of $\mathrm{Et}_{3} \mathrm{~N}$ as sacrificial donor. Liquid solution continuous wave (CW) EPR spectra of the photochemically-generated SQ-3 and SQ-5 matched well with those obtained chemically (see Section S5, Supporting Information), suggesting that both conditions lead to the formation of the same species. Moreover, in order to compare these species to those obtained electrochemically, the formation of the SQ intermediates was further investigated by UV/Vis spectroelectrochemistry (SEC). SEC experiments identified the 
characteristic absorption bands in the $400-500 \mathrm{~nm}$ region originating from the SOMO-LUMO transitions in the SQ state (Figure 3a, SQ band), ${ }^{47-49,51}$ while the band in the $300-350 \mathrm{~nm}$ domain originated from the quinoxaline wall absorption (Figure 3a, Qx band). ${ }^{29}$ The SQ spectroscopic fingerprint was found for both model compounds SQ-3 and SQ-5, as well as the bis-SQ cavitands 1 and 2 (for details, see Section S6, Supporting Information). Since the absorption in the 400-500 nm domain serves as evidence for the formation of the desired SQ species, we were able to monitor the photoreduction process by transient absorption spectroscopy and compare the transient absorption spectra (TAS) recorded upon photoreduction to the results of UV/Vis SEC. Both TAS (Figure 3b) and UV/Vis SEC (Figure 3a) featured the same spectroscopic indicators of the SQ formation with the absorption maxima in the $400-500 \mathrm{~nm}$ domain, identifying the photoreduction products as the target SQ intermediates (for details, see Sections S6-S7, Supporting Information).

Timescales of molecular processes can have a significant impact on the molecular function. ${ }^{52-54}$ In order to obtain the basis for the analysis of the conformational and binding properties, we estimated the photoreduction rates and the SQ lifetimes. The timescale of the cavitand conformational change should be slower than the photoreduction to occur as a secondary process in the SQ state, and lifetimes of the generated species should be in the order of minutes to enable the study of their gripping abilities. We performed luminescence lifetime measurements to determine the photoreduction rates (for details, see Section S7.1, Supporting Information) ${ }^{51,55-57}$ Stern-Volmer analysis revealed that the reduction occurs at a much faster rate $\left(2.3 \times 10^{9} \mathrm{M}^{-1} \mathrm{~s}^{-1}\right.$ for cavitand $\mathbf{1}$ and $3.3 \times 10^{9} \mathrm{M}^{-1} \mathrm{~s}^{-1}$ for cavitand 2$)$ than the conformational change, which takes place on the $\mu$ s scale..$^{32,58,59}$ Furthermore, lifetimes of the SQ species were estimated to be in the order of several hours under an inert argon atmosphere, as both transient 
absorption and EPR spectra confirmed their presence hours after the reduction. However, apart from having a long lived intermediate that can be obtained by a fast reduction process, the reversibility of the SQ-Q equilibrium was a prerequisite to exploiting the $\mathbf{S Q}$ intermediates as molecular devices. The SQ-Q equilibrium was thereby assessed by using UV/Vis spectroelectrochemistry over several reduction-oxidation cycles. The evolution of the two characteristic absorption maxima in the UV/Vis spectrum (Qx and SQ; Figure 3a) demonstrated reversibility over several cycles (Figure 3c), revealing potential utility of these SQ-based molecular switches.
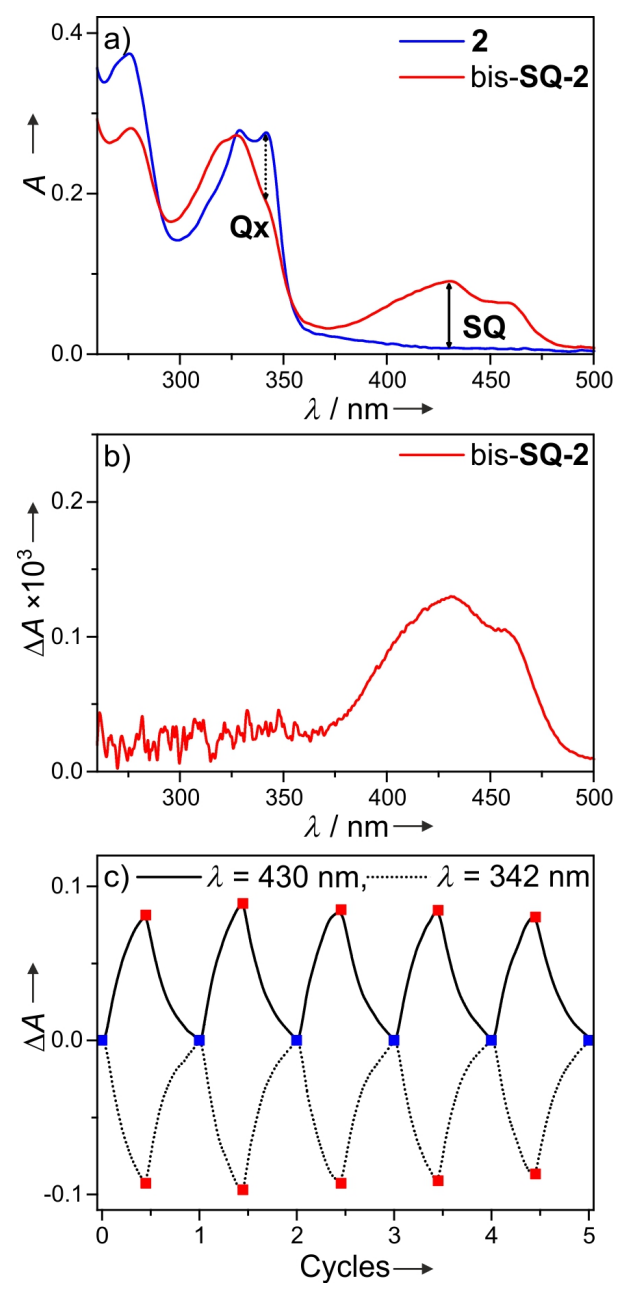

Figure 3. (a) UV/Vis spectra of the $\mathbf{Q}$ and the bis-SQ states of cavitand $\mathbf{2}(1 \mathrm{mM})$ in $n$ $\mathrm{Bu}_{4} \mathrm{NBF}_{4} / \mathrm{CH}_{2} \mathrm{Cl}_{2}(0.2 \mathrm{M})$ recorded during the controlled potential reduction at $-1.15 \mathrm{~V} \mathrm{vs}$. $\mathrm{Fc}^{+} / \mathrm{Fc}$ 
as an internal potential reference. Absorption maximum in the $400-500 \mathrm{~nm}$ region indicates the SQ formation (SQ band), whereas the 300-350 nm domain originates mainly from quinoxaline wall absorption (Qx band), as confirmed by the UV/Vis spectroscopy of model 4 (see Figure 4 and Section 6, Supporting Information). (b) Transient absorption spectrum of cavitand bis-SQ-2 $(0.94 \mathrm{mM})$ generated via photoreduction of 2 with $\left[\mathrm{Ru}(\mathrm{bpy})_{3}\right]^{2+}\left(3.1 \times 10^{-5} \mathrm{M}\right)$ in degassed $\mathrm{CH}_{2} \mathrm{Cl}_{2}$ solution under $\mathrm{Ar}$ atmosphere in presence of $\mathrm{Et}_{3} \mathrm{~N}(0.1 \mathrm{M})$ after a time delay of $2 \mathrm{~ms}$. The data is time averaged over 20 scans after excitation at $532 \mathrm{~nm}$ with laser pulses of $\sim 10 \mathrm{~ns}$ width (see Section S7, Supporting Information). The absorption in the 400-500 nm region indicates the SQ formation, whereas below $350 \mathrm{~nm}$ the optical density of the solution was too high to permit detection of any spectral changes associated with the photoexcitation. (c) Evolution of the absorption maxima in the UV/Vis spectrum presented in (a) over several switching cycles demonstrates the reversibility of the SQ-Q equilibrium.

The control and monitoring of the vase-kite equilibrium of cavitands is essential to their applicability as molecular grippers. Therefore, having methods to generate and identify the SQ intermediates at hand, we focused on the analysis of their conformational properties. Conformational equilibria between the vase and kite forms of cavitands $\mathbf{1}-\mathbf{2}$ in their $\mathbf{Q}$ and $\mathbf{H Q}$ states were previously studied by ${ }^{1} \mathrm{H}$ NMR spectroscopy. ${ }^{31}$ Despite being a powerful technique for evaluating conformations of resorcin[4]arene cavitands, NMR spectroscopy cannot be used to characterize the radical SQ states, since the electron-induced fast relaxation leads to line broadening and disappearance of NMR signals. ${ }^{60-62}$ An alternative technique that can provide information about the cavitand conformation is $\mathrm{UV} / \mathrm{Vis}$ spectroscopy, ${ }^{29}$ with spectroscopic indication of the cavitand conformation originating from the quinoxaline flap absorption in the 300-350 $\mathrm{nm}$ region. We verified the origin of the absorption in this domain by UV/Vis 
spectroscopy of quinoxaline model $\mathbf{4}$, which corresponds to a single quinoxaline cavitand wall. Moreover, we demonstrated that quinone-quinoxaline-based cavitands $\mathbf{1}$ and $\mathbf{2}$ in either the $\mathbf{Q}$ or HQ state exhibit similar UV/Vis spectral features in the quinoxaline absorption domain (for details, see Section 6, Supporting Information). In order to identify the kite and vase conformations in the $\mathbf{Q}$ state by UV/Vis spectroscopy, we utilized the solvent and temperature influence on the vase-kite equilibrium. The stabilization of the kite conformation was shown to be dominant in chlorinated solvents, such as $\mathrm{CH}_{2} \mathrm{Cl}_{2}$ and $\mathrm{CHCl}_{3}$, whereas the vase conformation is stabilized in polar or aromatic solvents, such as tetrahydrofuran (THF) or benzene at ambient temperatures, which was confirmed by NMR spectroscopy. ${ }^{24,26,31}$ Lower temperatures are known to favor the kite conformation, while elevated temperatures shift the equilibrium towards the vase form. ${ }^{24,28}$ We identified the kite conformation of cavitands $\mathbf{1}$ and $\mathbf{2}$ in their $\mathbf{Q}$ state to feature two absorption maxima at $344 \mathrm{~nm}$ and $332 \mathrm{~nm}$ in $\mathrm{CH}_{2} \mathrm{Cl}_{2}$, whereas the kite-to-vase conversion correlated with $\mathrm{a} \approx 15 \mathrm{~nm}$ hypsochromic shift of these absorption bands in THF (Figure 4a).

Such effects were not evident in the case of model compounds 3-5, whose UV/Vis spectra in $\mathrm{CH}_{2} \mathrm{Cl}_{2}$ and THF were superimposable (for model 4, see Figure 4b; for other species, see Section S6.1, Supporting Information). The hypsochromic shift of the quinoxaline UV/Vis absorption can thereby serve as indicator for the conformational changes in the cavitand systems.

With the advantage of using UV/Vis spectroscopy in monitoring the vase-kite interconversion, we analyzed the conformational properties of the cavitand systems $\mathbf{1}$ and $\mathbf{2}$ in the bis-SQ state by UV/Vis spectroelectrochemistry. While the change of solvent or temperature did not affect the SQ absorption in the 400-500 $\mathrm{nm}$ range, the quinoxaline absorption domain between $300 \mathrm{~nm}$ and $350 \mathrm{~nm}$ revealed conformational changes of the cavitands. The SQ states in THF at ambient temperature directly corresponded to the vase conformations of the $\mathbf{Q}$ state, 
with two absorption maxima at $329 \mathrm{~nm}$ and $320 \mathrm{~nm}$ (Figure 4c). However, the UV/Vis spectrum in $\mathrm{CH}_{2} \mathrm{Cl}_{2}$ at ambient temperature demonstrated $\mathrm{a} \approx 10 \mathrm{~nm}$ hypsochromic shift indicative of the kite-to-vase conversion (Figure 4d). Such spectral changes were less pronounced at lower temperatures in $\mathrm{CH}_{2} \mathrm{Cl}_{2}$ (for details see Section S6.2, Supporting Information). The equilibrium shift towards the vase-like conformation in $\mathrm{CH}_{2} \mathrm{Cl}_{2}$ at ambient temperature could stem from the charge redistribution inside the cavitand backbone resulting from the SQ radical anion formation, which could lead to its stabilization through electrostatic interactions with the neighboring quinoxaline flaps. A similar effect can result from the noncovalent interactions with the solvent molecules that bind to the cavity and therefore stabilize the vase conformation. ${ }^{4,24,25}$
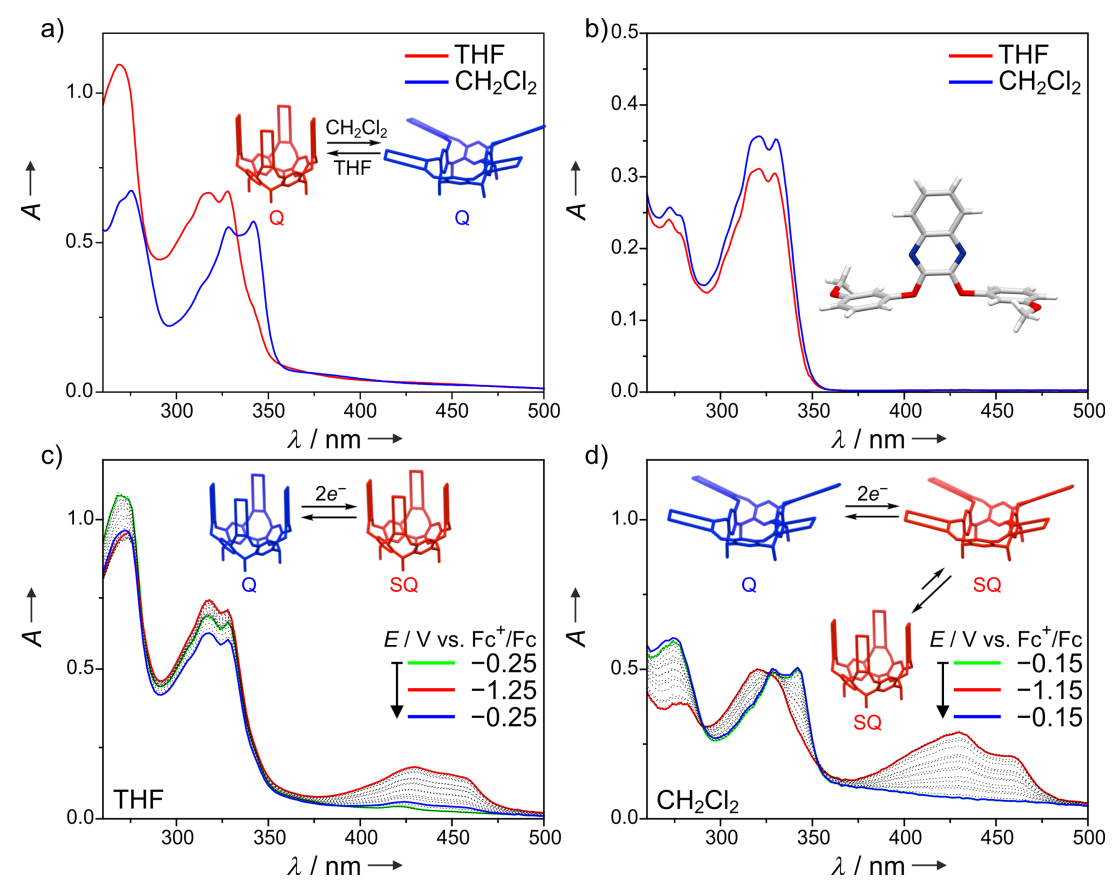

Figure 4. (a) UV/Vis spectra of cavitand $\mathbf{2}$ in the $\mathbf{Q}$ state in $\mathrm{CH}_{2} \mathrm{Cl}_{2}$ (kite form) and THF (vase form, as verified by the ${ }^{1} \mathrm{H}$ NMR spectroscopy ${ }^{31}$ ) with a schematic of a solvent-induced conformational switch between the kite and vase forms in the $\mathbf{Q}$ state. Kite-to-vase conversion correlates with $\mathrm{a} \approx 15 \mathrm{~nm}$ hypsochromic shift of the absorption bands in THF. (b) UV/Vis 
spectra of model 4 in $\mathrm{CH}_{2} \mathrm{Cl}_{2}$ and THF, which are essentially superimposable due to the lack of conformational transitions. Model 4 is represented by its crystal structure (for details see Section S3, Supporting Information). (c) UV/Vis spectroelectrochemistry of cavitand 2 (1 mM) in $n-\mathrm{Bu}_{4} \mathrm{NBF}_{4} / \mathrm{THF}(0.2 \mathrm{M})$ with a schematic of a redox switch between the bis-SQ (red) and the $\mathbf{Q}$ (blue) state in the vase forms. Two absorption maxima at $329 \mathrm{~nm}$ and $320 \mathrm{~nm}$ correspond to the vase conformation, as demonstrated in (a) and verified by ${ }^{1} \mathrm{H}$ NMR spectroscopy. ${ }^{31}$ (d) $\mathrm{UV} / \mathrm{V}$ is spectroelectrochemistry of cavitand $2(1 \mathrm{mM})$ in $n-\mathrm{Bu}_{4} \mathrm{NBF}_{4} / \mathrm{CH}_{2} \mathrm{Cl}_{2}(0.2 \mathrm{M})$ with a schematic of a redox switch between the $\mathbf{Q}$ (blue) in the kite form and the bis-SQ (red) state in the kite and vase forms. The kite-vase equilibrium shift towards the vase conformation in the bis-SQ state is indicated by the $\approx 10 \mathrm{~nm}$ hypsochromic shift of the absorption in the $300-350 \mathrm{~nm}$ domain and verified by EPR spectroscopy (for details, see Section S5, Supporting Information). The spectra correspond to the potentials indicated by colored lines in the legend. $\mathrm{THF}=$ tetrahydrofuran.

The conformational analysis of triplet bis-SQ cavitands 1-2 can be supported by their unique paramagnetic behavior, which acts as a powerful tool in the evaluation of their geometry. Triplet organic bi-radicals behave as nanomagnets, demonstrating Zero Field Splitting (ZFS) in absence of an external magnetic field. ${ }^{44,49,63,64}$ This is the result of an additional splitting of the energy levels induced by the anisotropic dipolar interactions of the magnetic moments of the two electrons, and can be characterized by the $D$ and $E$ parameters. ${ }^{44,65}$ Since the $D$ parameter is dependent on the distance between the triplet radical sites, it offers a unique indicator for differentiating between the cavitand conformations. The ZFS tensor of the triplet bis-SQ-2 dianion in $\mathrm{CH}_{2} \mathrm{Cl}_{2}$ is characterized by a $D$ value of $78.1 \mathrm{MHz}$ and an $E / D$ ratio of 0.04 (Table 1). Assuming a dominantly dipolar character of the ZFS tensor and using the point dipole 
approximation $^{46,65}$ enables us to estimate a distance of $10.0 \pm 0.5 \AA$ between the sites of the two unpaired electrons, which is in excellent agreement with the distance between the two $\mathbf{Q}$ walls in the vase conformation of the cavitand (Figure 5a). The structure of the neutral cavitand optimized by DFT calculations at the B3LYP/6-31G(d) level of theory shows a distance of $9.9 \AA$, matching well the distance observed in the cavitand's crystal structure featuring 1,4 dithiane as guest encapsulated in the vase form (Figure 5c; for details, see Section S3, Supporting Information). ${ }^{4,31}$ For the triplet bis-SQ-2 state, the Coulombic repulsion of the two charged semiquinones resulted in a slightly larger distance of $11 \AA$ (Figure $5 b$; for details, see Sections S9, Supporting Information). Nevertheless, both values are in agreement with the experiment within the level of uncertainty for distance determination by EPR spectroscopy, providing verification of the kite-vase equilibrium shift towards the vase geometry in the triplet bis-SQ state of cavitands 1 and 2 (for details, see Section S5, Supporting Information). 
a)

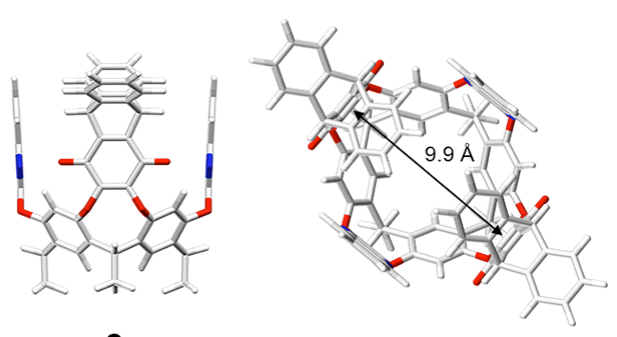

2

b)

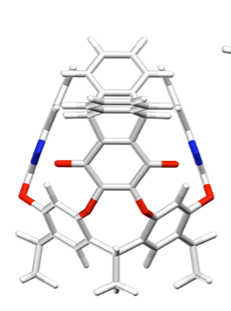

bis-SQ-2
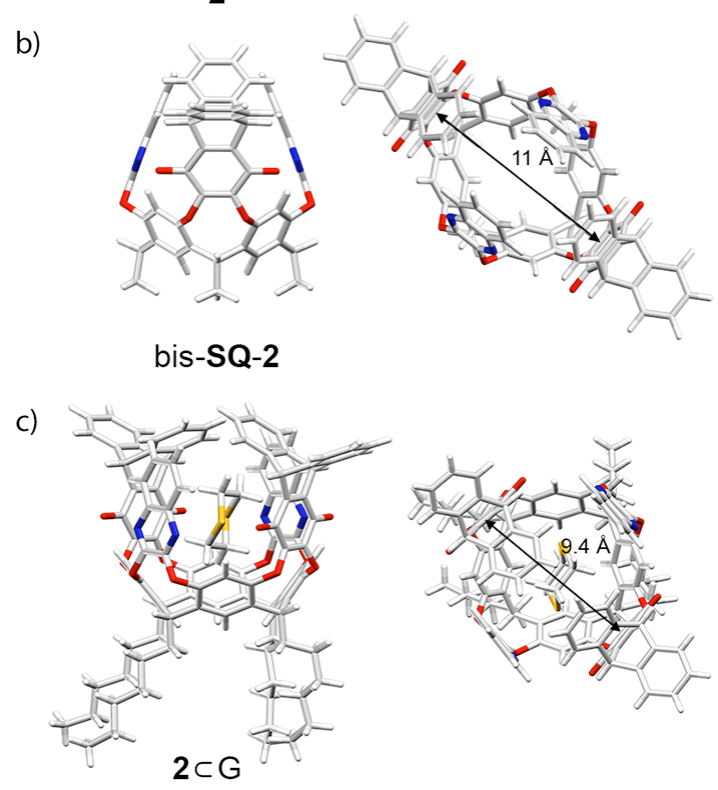

Figure 5. Optimized geometries (DFT B3LYP/6-31G(d)) of the vase conformations of cavitand $\mathbf{2}$ in the (a) $\mathbf{Q}$ and (b) $\mathbf{S Q}$ redox states. Hexyl chains are substituted by methyl groups. (c) Crystal structure of cavitand $\mathbf{2}$ in the $\mathbf{Q}$ state with a guest molecule ( $\mathrm{G}=1$,4-dithiane) inside the cavity $(2 \subset G)$. Side (left) and top (right) views are represented with distances between the redox-active quinone walls.

Another indicator of the conformational preference of the cavitands is their gripping ability. Binding properties of the quinone-based cavitands were already shown to be enhanced in the presence of triptycene units, particularly under conditions of a favored vase conformation, as upon binding the cavitand adopts a closed (vase) form (Figure 5c). ${ }^{24,25,31}$ Moreover, sixmembered cyclic molecules were verified as suitable neutral guests for quinone-quinoxaline- 
based cavitand hosts. ${ }^{25}$ Relying on these known cavitand features, we compared binding properties of triptycene cavitand $\mathbf{2}$ in three different redox states with several representative guest molecules (cyclohexane, 1,4-dioxane, 1,4-dithiane, piperazine, and 1,4-cyclohexadione; for details see Section S8, Supporting Information). Binding constants in reduced HQ and oxidized Q states were evaluated by ${ }^{1} \mathrm{H}$ NMR spectroscopy in mesitylene- $d_{12}$ as a non-competing solvent at room temperature, ${ }^{25}$ whereas studies in the intermediary SQ state were performed by CV and square wave voltammetry (SWV) in $\mathrm{CH}_{2} \mathrm{Cl}_{2} \cdot{ }^{66-68}$ We analyzed the binding properties of the SQ state in $\mathrm{CH}_{2} \mathrm{Cl}_{2}$, despite its role as a competing solvent that can bind to the cavity in the vase form and thereby result in lower values of the obtained binding constants. Remarkably, not only were the binding constants higher in the SQ state under these conditions, but each of the three redox states (Q, SQ, and HQ) demonstrated different binding properties (Table 2). This behavior of the cavitand $\mathbf{2}$ in the SQ state highlights its potential ability to act as a redoxswitchable molecular gripper.

Table 2. Binding constants of $\mathbf{2}$ in $\mathbf{Q}\left(K_{\mathrm{a}}^{\mathrm{Q}}, \mathrm{M}^{-1}\right), \mathbf{H Q}\left(K_{\mathrm{a}}^{\mathrm{HQ}}, \mathrm{M}^{-1}\right)$, and $\mathbf{S Q}\left(K_{\mathrm{a}}^{\mathrm{SQ}}, \mathrm{M}^{-1}\right)$ states for different guests at $293 \mathrm{~K}$.

\begin{tabular}{|c|c|c|c|}
\hline Guest & $K_{\mathrm{a}}^{\mathrm{Q}}, \mathrm{M}^{-1 \mathrm{a}}$ & $K_{\mathrm{a}}^{\mathrm{SQ}}, \mathrm{M}^{-1 \mathrm{~b}}$ & $K_{\mathrm{a}}^{\mathrm{HQ}}, \mathrm{M}^{-1 \mathrm{a}}$ \\
\hline & $15^{31}$ & $>15\left(51^{c}\right)$ & $3.1^{31}$ \\
\hline & 4 & 949 & $<0.1$ \\
\hline & 127 & $>127\left(399^{c}\right)$ & 40 \\
\hline & 42 & $--^{d}$ & $<0.1$ \\
\hline & 18 & 180 & $<1$ \\
\hline
\end{tabular}


${ }^{\mathrm{a}} K_{\mathrm{a}}$ values were determined by integration of the ${ }^{1} \mathrm{H}$ NMR resonances of the relevant species in mesitylene- $d_{12}$, relative to 1,3,5-trimethoxybenzene as an internal standard. Errors in $K_{\mathrm{a}}$ values are estimated to be roughly $20 \% .{ }^{31}{ }^{\mathrm{b}} K_{\mathrm{a}}$ values were determined by cyclic voltammetry or squarewave voltammetry of the relevant species in $\mathrm{CH}_{2} \mathrm{Cl}_{2}$ relying on the shift of the redox potential and the square electrochemical scheme in accordance with previously reported experimental procedures. ${ }^{66-68}$ 'In these cases, simulation is recommended to quantify the $K_{\mathrm{a}}$ with more certainty since binding constants are in the same order as in the oxidized states. ${ }^{68}$ Influence of hydrogen bonding on the shift of the redox potentials cannot be directly excluded in the evaluation of the binding constant.

In summary, this work reports the electronic, conformational, and binding properties of redoxactive cavitand systems $\mathbf{1 - 2}$ in the paramagnetic semiquinone dianion (SQ) state that were evaluated using electrochemistry, UV/Vis spectroelectrochemistry, EPR and transient absorption spectroscopy, DFT calculations, and the analysis of model systems. Three redox states of the triptycene-based cavitand $\mathbf{2}(\mathbf{Q}, \mathbf{S Q}$, and $\mathbf{H Q})$ were shown to exhibit different binding properties in their vase conformation, and complexation was particularly pronounced for the paramagnetic SQ intermediate. The reversibility of $\mathbf{S Q}-\mathbf{Q}$ equilibrium, long lifetimes of the $\mathbf{S Q}$ species under inert conditions, their switchable magnetic and binding properties, as well as responsiveness to electrical stimuli, render them promising for future applications in molecular engineering. Ongoing work is focused on further exploiting their potential applicability as photoredoxswitchable molecular devices.

\section{ASSOCIATED CONTENT}

Supporting Information. Synthesis, NMR Spectroscopy, Crystal Structure Data, Electrochemistry, EPR Spectroscopy, UV/Vis Spectroscopy and UV/Vis/NIR Spectroelectrochemistry, Time-Resolved Luminescence and Transient Absorption Spectroscopy, Binding Studies, DFT Calculations. This material is available free of charge at http://pubs.acs.org (PDF). 


\section{AUTHOR INFORMATION}

\section{Notes}

The authors declare no competing financial interests.

\section{ACKNOWLEDGMENT}

This work was supported by the Swiss National Science Foundation (SNF) Grant 200020159802, Scientific Grant Agency of the Slovak Republic (Project 1/0307/14), and Max Planck Society. J.M. acknowledges the receipt of a fellowship from the Dositeja Fund for Young Talents for international studies. The authors are grateful to Christoph Laurich and Petra Höfer (Max Planck Institute for Chemical Energy Conversion) for technical assistance, Dr. Michael Solar (ETH Zurich) for efforts in X-ray crystallographic analysis, and Dr. Bruno Bernet (ETH Zurich) for proofreading the manuscript.

\section{REFERENCES}

(1) Kay, E. R.; Leigh, D. A. Rise of the Molecular Machines. Angew. Chem. Int. Ed. 2015, $54,2-11$.

(2) Balzani, V.; Gómez-López, M.; Stoddart, J. F. Molecular Machines. Acc. Chem. Res. 1998, 31, 405-414.

(3) Abendroth, J. M.; Bushuyev, O. S.; Weiss, P. S.; Barrett, C. J. Controlling Motion at the Nanoscale: Rise of the Molecular Machines. ACS Nano 2015, 9, 7746-7768.

(4) Pochorovski, I.; Ebert, M.-O.; Gisselbrecht, J.-P.; Boudon, C.; Schweizer, W. B.; Diederich, F. Redox-Switchable Resorcin[4]arene Cavitands: Molecular Grippers. J. Am. Chem. Soc. 2012, 134, 14702-14705. 
(5) Sánchez-Lozano, M.; Estévez, C. M.; Hermida-Ramón, J. M. Theoretical Design of Molecular Grippers for Anion Recognition Based on Subporphyrazines and Subphthalocyanines. Phys. Chem. Chem. Phys. 2014, 16, 6108-6117.

(6) Huang, F.; Isaacs, L. Guest Editorial: Responsive Host-Guest Systems. Acc. Chem. Res. 2014, 47, 1923-1924.

(7) Javor, S.; Rebek, J., Jr. Activation of a Water-Soluble Resorcinarene Cavitand at the Water-Phosphocholine Micelle Interface. J. Am. Chem. Soc. 2011, 133, 17473-17478.

(8) Adhikari, B. B.; Fujii, A.; Schramm, M. P. Calixarene-Mediated Liquid-Membrane Transport of Choline Conjugates. Eur. J. Org. Chem. 2014, 2972-2979.

(9) Suman, M.; Freddi, M.; Massera, C.; Ugozzoli, F.; Dalcanale, E. Rational Design of Cavitand Receptors for Mass Sensors. J. Am. Chem. Soc. 2003, 125, 12068-12069.

(10) Pinalli, R.; Suman, M.; Dalcanale, E. Cavitands at Work: From Molecular Recognition to Supramolecular Sensors. Eur. J. Org. Chem. 2004, 451-462.

(11) Ryan, D. A.; Rebek, J., Jr. A Carbohydrate-Conjugated Deep Cavitand Permits Observation of Caviplexes in Human Serum. J. Am. Chem. Soc. 2011, 133, 19653-19655.

(12) Lledó, A.; Rebek, J., Jr. Deep Cavitand Receptors with pH-Independent Water Solubility. Chem. Commun. 2010, 46, 8630-8632.

(13) Zhu, S. S.; Staats, H.; Brandhorst, K.; Grunenberg, J.; Gruppi, F.; Dalcanale, E.; Lützen, A.; Rissanen, K.; Schalley, C. A. Anion Binding to Resorcinarene-Based Cavitands: the Importance of C-H*Anion Interactions. Angew. Chem. Int. Ed. 2008, 47, 788-792. 
(14) Ma, X.; Zhao, Y. Biomedical Applications of Supramolecular Systems Based on Host-Guest Interactions. Chem. Rev. 2014, 115, 7794-7839.

(15) Bianchi, F.; Pinalli, R.; Ugozzoli, F.; Spera, S.; Careri, M.; Dalcanale, E. Cavitands as Superior Sorbents for Benzene Detection at Trace Level. New J. Chem. 2003, 27, 502-509.

(16) Gibb, C. L. D.; Sundaresan, A. K.; Ramamurthy, V; Gibb, B. C. Templation of the Excited-State Chemistry of $\alpha$-(N-Alkyl) Dibenzyl Ketones: How Guest Packing Within a Nanoscale Supramolecular Capsule Influences Photochemistry. J. Am. Chem. Soc. 2008, 130, 4069-4080.

(17) Ewell, J.; Gibb, B. C.; Rick, S. W. Water Inside a Hydrophobic Cavitand Molecule. J. Phys. Chem. B 2008, 112, 10272-10279.

(18) Richeter, S.; Rebek, J., Jr. Catalysis by a Synthetic Receptor Sealed at One End and Functionalized at the Other. J. Am. Chem. Soc. 2004, 126, 16280-16281.

(19) Gissot, A.; Rebek, J., Jr. A Functionalized, Deep Cavitand Catalyzes the Aminolysis of a Choline Derivative. J. Am. Chem. Soc. 2004, 126, 7424-7425.

(20) Berryman, O. B.; Sather, A. C.; Lledó, A.; Rebek, J., Jr. Switchable Catalysis with a Light-Responsive Cavitand. Angew. Chem. Int. Ed. 2011, 50, 9400-9403.

(21) Purse, B. W.; Rebek, J., Jr. Functional Cavitands: Chemical Reactivity in Structured Environments. Proc. Nat. Acad. Sci. U.S.A. 2005, 102, 10777-10782.

(22) Ajami, D.; Rebek, J., Jr. Coiled Molecules in Spring Loaded Devices. J. Am. Chem. Soc. 2006, 128, 15038-15039. 
(23) Azov, V. A.; Beeby, A.; Cacciarini, M.; Cheetham, A. G.; Diederich, F.; Frei, M.; Gimzewski, J. K.; Gramlich, V.; Hecht, B.; Jaun, B.; et al. Resorcin[4]arene Cavitand-Based Molecular Switches. Adv. Funct. Mater. 2006, 16, 147-156.

(24) Pochorovski, I.; Diederich, F. Development of Redox-Switchable Resorcin[4]arene Cavitands. Acc. Chem. Res. 2014, 47, 2096-2105.

(25) Pochorovski, I.; Milić, J.; Kolarski, D.; Gropp, C.; Schweizer, W. B.; Diederich, F. Evaluation of Hydrogen-Bond Acceptors for Redox-Switchable Resorcin[4]arene Cavitands. J. Am. Chem. Soc. 2014, 136, 3852-3858.

(26) Bryant, J. A.; Ericson, J. L.; Cram, D. J. High Preorganization of Large Lipophilic Surfaces Common to Two Complexing Partners Provides High Binding Free Energies That Vary Dramatically with Changes in Organic Solvent Composition. J. Am. Chem. Soc. 1990, 112, $1255-1256$.

(27) Roncucci, P.; Pirondini, L.; Paderni, G.; Massera, C.; Dalcanale, E.; Azov, V. A.; Diederich, F. Conformational Behavior of Pyrazine-Bridged and Mixed-Bridged Cavitands: A General Model for Solvent Effects on Thermal "Vase-Kite" Switching. Chem-Eur. J. 2006, 12, 4775-4784.

(28) Moran, J. R.; Karbach, S.; Cram, D. J. Cavitands: Synthetic Molecular Vessels. J. Am. Chem. Soc. 1982, 104, 5826-5828.

(29) Skinner, P. J.; Cheetham, A. G.; Beeby, A.; Gramlich, V.; Diederich, F. Conformational Switching of Resorcin[4]arene Cavitands by Protonation. Helv. Chim. Acta 2001, 84, 21462153. 
(30) Frei, M.; Marotti, F.; Diederich, F. Zn(II)-Induced Conformational Control of Amphiphilic Cavitands in Langmuir Monolayers. Chem. Commun. 2004, 1362-1363.

(31) Pochorovski, I.; Boudon, C.; Gisselbrecht, J.-P.; Ebert, M.-O.; Schweizer, W. B.; Diederich, F. Quinone-Based, Redox-Active Resorcin[4]arene Cavitands. Angew. Chem. Int. Ed. 2012, 51, 262-266.

(32) Azov, V. A.; Jaun, B.; Diederich, F. NMR Investigations Into the Vase-Kite Conformational Switching of Resorcin[4]arene Cavitands. Helv. Chim. Acta 2004, 87, 449-462.

(33) Berryman, O. B.; Sather, A. C.; Rebek, J., Jr. A Light Controlled Cavitand Wall Regulates Guest Binding. Chem. Commun. 2011, 47, 656-658.

(34) Yang, Y.-W.; Sun, Y.-L.; Song, N. Switchable Host-Guest Systems on Surfaces. Acc. Chem. Res. 2014, 47, 1950-1960.

(35) Song, C.; Swager, T. M. $\pi$-Dimer Formation as the Driving Force for Calix[4]areneBased Molecular Actuators. Org. Lett. 2008, 10, 3575-3578.

(36) Brouwer, A. M.; Frochot, C.; Gatti, F. G.; Leigh, D. A.; Mottier, L.; Paolucci, F.; Roffia, S.; Wurpel, G. W. H. Photoinduction of Fast, Reversible Translational Motion in a HydrogenBonded Molecular Shuttle. Science 2001, 291, 2124-2128.

(37) Gobbi, L.; Seiler, P.; Diederich, F. A Novel Three-Way Chromophoric Molecular Switch: pH and Light Controllable Switching Cycles. Angew. Chem. Int. Ed. Engl. 1999, 38, $674-678$. 
(38) Liu, C.-G.; Su, Z.-M.; Guan, X.-H.; Muhammad, S. Redox and Photoisomerization Switching the Second-Order Nonlinear Optical Properties of a Tetrathiafulvalene Derivative Across Six States: a DFT Study. J. Phys. Chem. C 2011, 115, 23946-23954.

(39) De Silva, A. P.; Gunaratne, H. Q. N.; Gunnlaugsson, T.; Huxley, A. J. M.; McCoy, C. P.; Rademacher, J. T.; Rice, T. E. Signaling Recognition Events with Fluorescent Sensors and Switches. Chem. Rev. 1997, 97, 1515-1566.

(40) Fioravanti, G.; Haraszkiewicz, N.; Kay, E. R.; Mendoza, S. M.; Bruno, C.; Marcaccio, M.; Wiering, P. G.; Paolucci, F.; Rudolf, P.; Brouwer, A. M.; Leigh, D. A. Three State RedoxActive Molecular Shuttle That Switches in Solution and on a Surface. J. Am. Chem. Soc. 2008, $130,2593-2601$.

(41) Karsili, T. N. V.; Tuna, D.; Ehrmaier, J.; Domcke, W. Photoinduced Water Splitting via Benzoquinone and Semiquinone Sensitisation. Phys. Chem. Chem. Phys. 2015, 17, 3218332193.

(42) Wipf, D.; Wehmeyer, K. R.; Wightman, R. M. Disproportionation of Quinone Radical Anions in Protic Solvents at High pH. J. Org. Chem. 1986, 51, 4760-4764.

(43) Guin, P. S.; Das, S.; Mandal, P. C. Electrochemical Reduction of Quinones in Different Media: a Review. Int. J. Electrochem. 2011, Article ID: 816202, 1-22.

(44) Schweiger, A.; Jeschke, G., Principles of Pulse Electron Paramagnetic Resonance. Oxford Univ. Press: Oxford, 2001.

(45) Takui, T.; Sato, K.; Shiomi, D.; Itoh, K.; Kaneko, T.; Tsuchida, E.; Nishide, H. FT Pulsed ESR/Electron Spin Transient Nutation (ESTN) Spectroscopy Applied to High-Spin Systems in 
Solids; Direct Evidence of a Topologically Controlled High-Spin Polymer as Models for Quasi ID Organic Ferro- and Superpara-Magnets. Mol. Crys. Liq. Cryst. 1996, 279, 155-176.

(46) Cox, N.; Retegan, M.; Neese, F.; Pantazis, D. A.; Boussac, A.; Lubitz, W. Electronic Structure of the Oxygen-Evolving Complex in Photosystem II Prior to O-O Bond Formation. Science 2014, 345, 804-808.

(47) Vân Anh, N.; Williams, R. M. Bis-Semiquinone (Bi-Radical) Formation by Photoinduced Proton Coupled Electron Transfer in Covalently Linked Catechol-Quinone Systems: Aviram's Hemiquinones Revisited. Photochem. Photobiol. Sci. 2012, 11, 957-961.

(48) Yuasa, J.; Yamada, S.; Fukuzumi, S. Direct EPR Detection of a Hydrogen-Bonded Complex Between a Semiquinone Radical Anion and a Protonated Amino Acid, and Electron Transfer Driven by Hydrogen Bonding. Angew. Chem. Int. Ed. 2007, 46, 3553-3555.

(49) Sun, C.; Taguchi, A. T.; Beal, N. J.; O’Malley, P. J.; Dikanov, S. A.; Wraight, C. A. Regulation of the Primary Quinone Binding Conformation by the H Subunit in Reaction Centers From Rhodobacter Sphaeroides. J. Phys. Chem. Lett. 2015, 6, 4541-4546.

(50) Schweinfurth, D.; Zalibera, M.; Kathan, M.; Shen, C.; Mazzolini, M.; Trapp, N.; Crassous, J.; Gescheidt, G.; Diederich, F. Helicene Quinones: Redox-Triggered Chiroptical Switching and Chiral Recognition of the Semiquinone Radical Anion Lithium Salt by Electron Nuclear Double Resonance Spectroscopy. J. Am. Chem. Soc. 2014, 136, 13045-13052.

(51) Hankache, J.; Hanss, D.; Wenger, O. S. Hydrogen-Bond Strengthening Upon Photoinduced Electron Transfer in Ruthenium-Anthraquinone Dyads Interacting with Hexafluoroisopropanol or Water. J. Phys. Chem. A 2012, 116, 3347-3358. 
(52) Denisov, S. A.; Gan, Q.; Wang, X.; Scarpantonio, L.; Ferrand, Y.; Kauffmann, B.; Jonusauskas, G.; Huc, I.; McClenaghan, N. D. Electronic Energy Transfer Modulation in a Dynamic Foldaxane: Proof-of-Principle of a Lifetime-Based Conformation Probe. Angew. Chem. Int. Ed. 2015, 54, 1-7.

(53) Gan, Q.; Ferrand, Y.; Bao, C.; Kauffmann, B.; Grélard, A.; Jiang, H.; Huc, I. Helix-Rod Host-Guest Complexes with Shuttling Rates Much Faster Than Disassembly. Science 2011, 331, $1172-1175$.

(54) Pochorovski, I.; Knehans, T.; Nettels, D.; Müller, A. M.; Schweizer, W. B.; Caflisch, A.; Schuler, B.; Diederich, F. Experimental and Computational Study of BODIPY Dye-Labeled Cavitand Dynamics. J. Am. Chem. Soc. 2014, 136, 2441-2449.

(55) Nomrowski, J.; Wenger, O. S. Photoinduced PCET in Ruthenium-Phenol Systems: Thermodynamic Equivalence of Uni- and Bidirectional Reactions. Inorg. Chem. 2015, 54, 36803687.

(56) Wenger, O. S. Photoswitchable Mixed Valence. Chem. Soc. Rev. 2012, 41, 3772-3779.

(57) Bonin, J.; Routier, M. Transient Absorption Spectroscopy Studies of Proton-Coupled Electron Transfers. Artif. Photosynth. 2013, 1, 6-15.

(58) Tang, H.; de Oliveira, C. S.; Sonntag, G.; Gibb, C. L. D.; Gibb, B. C.; Bohne, C. Dynamics of a Supramolecular Capsule Assembly with Pyrene. J. Am. Chem. Soc. 2012, 134, $5544-5547$.

(59) Berryman, O. B.; Dube, H.; Rebek, J., Jr. Photophysics Applied to Cavitands and Capsules. Isr. J. Chem. 2011, 51, 700-709. 
(60) Li, H.; Fahrenbach, A. C.; Coskun, A.; Zhu, Z.; Barin, G.; Zhao, Y.-L.; Botros, Y. Y.; Sauvage, J.-P.; Stoddart, J. F. A Light-Stimulated Molecular Switch Driven by Radical-Radical Interactions in Water. Angew. Chem. Int. Ed. 2011, 50, 6782-6788.

(61) Fahrenbach, A. C.; Zhu, Z.; Cao, D.; Liu, W.-G.; Li, H.; Dey, S. K.; Basu, S.; Trabolsi, A.; Botros, Y. Y.; Goddard, W. A.; et al. Radically Enhanced Molecular Switches. J. Am. Chem. Soc. 2012, 134, 16275-16288.

(62) Trabolsi, A.; Khashab, N.; Fahrenbach, A. C.; Friedman, D. C.; Colvin, M. T.; Cotí, K. K.; Benítez, D.; Tkatchouk, E.; Olsen, J.-C.; Belowich, M. E.; et al. Radically Enhanced Molecular Recognition. Nature Chem 2009, 2, 42-49.

(63) Shultz, D. A.; Fico, R. M., Jr.; Bodnar, S. H.; Kumar, R. K.; Vostrikova, K. E.; Kampf, J. W.; Boyle, P. D. Trends in Exchange Coupling for Trimethylenemethane-Type Bis(Semiquinone) Biradicals and Correlation of Magnetic Exchange with Mixed Valency for Cross-Conjugated Systems. J. Am. Chem. Soc. 2003, 125, 11761-11771.

(64) Caneschi, A.; Dei, A.; Lee, H.; Shultz, D. A.; Sorace, L. Ferromagnetically Coupled Bis(Semiquinone) Ligand Enforces High-Spin Ground States in Bis-Metal Complexes. Inorg. Chem. 2001, 40, 408-411.

(65) Munzrová, M. L. DFT Calculations of EPR Hyperfine Coupling Tensors. In Calculation of NMR and EPR Parameters. Theory and Applications. Kaupp, M., Buhl, M., Malkin, V. G., Eds.; Wiley-VCH: Weinheim, 2004; 463-482. 
(66) Gómez-Kaifer, M.; Reddy, P. A.; Gutsche, C. D.; Echegoyen, L. Electroactive Calixarenes. 1. Redox and Cation Binding Properties of Calixquinones. J. Am. Chem. Soc. 1994, $116,3580-3587$.

(67) Boulas, P. L.; Gómez-Kaifer, M.; Echegoyen, L. Electrochemistry of Supramolecular Systems. Angew. Chem. Int. Ed. 1998, 37, 216-247.

(68) Miller, S. R.; Gustowski, D. A.; Chen, Z.-h.; Gokel, G. W.; Echegoyen, L.; Kaifer, A. E. Rationalization of the Unusual Electrochemical Behavior Observed in Lariat Ethers and Other Reducible Macrocyclic Systems. Anal. Chem. 1988, 60, 2021-2024. 


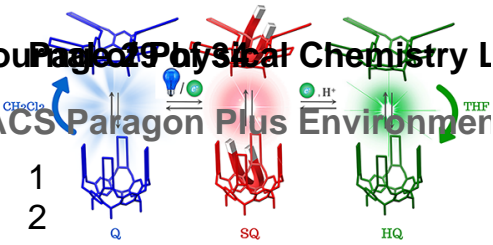


The Journatof Physical ConemiBtrge Lotets34

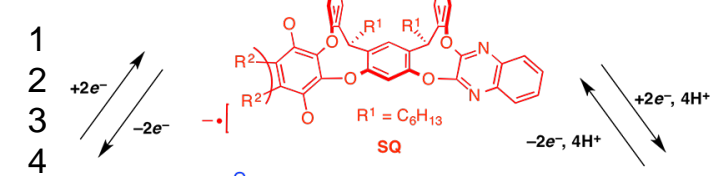

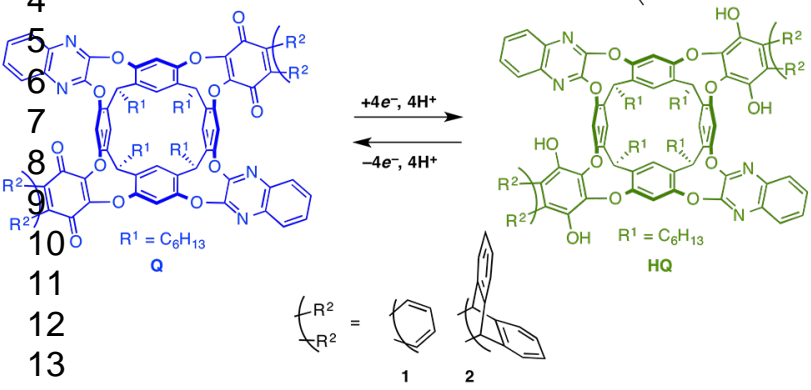

$-14$

15

16
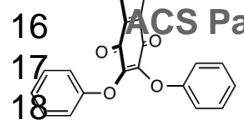

3

Mus En

4

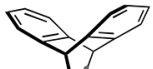

10

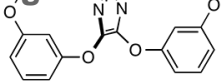

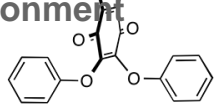

5 


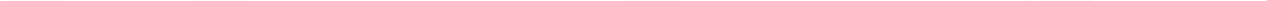




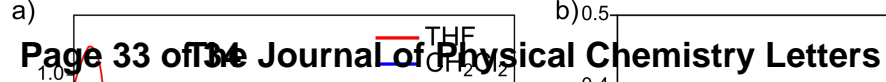
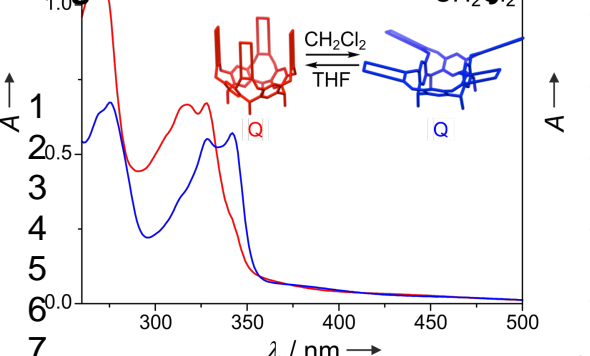

0.4

$-\mathrm{CH}_{2} \mathrm{Cl}_{2}$

8

8

$\uparrow$
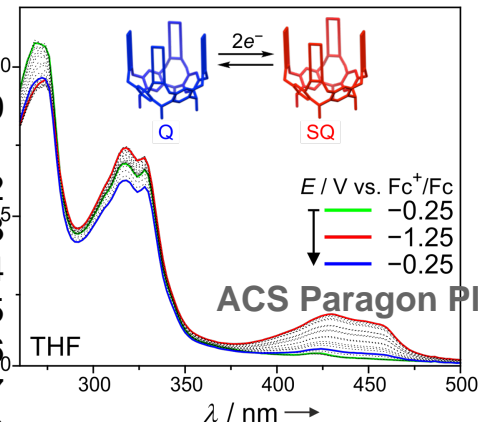

11

13

14

15

16.0 THF

17

d)

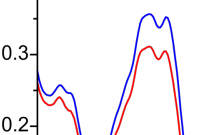

0.0

300

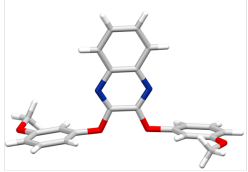

$0.1-$

$\lambda / \mathrm{nm} \longrightarrow$

$450 \quad 500$

1.0

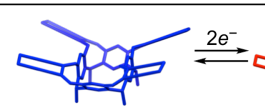

Q

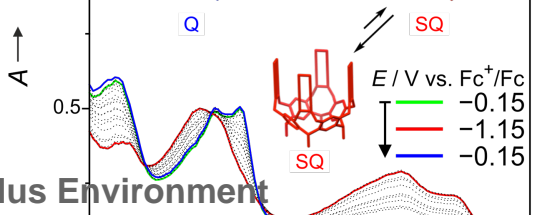

$0.0 \frac{\mathrm{CH}_{2} \mathrm{Cl}_{2}}{300}$

350

$\lambda / \mathrm{nm} \rightarrow$ 
The Journal of Physical Chefraigsti4etto4s

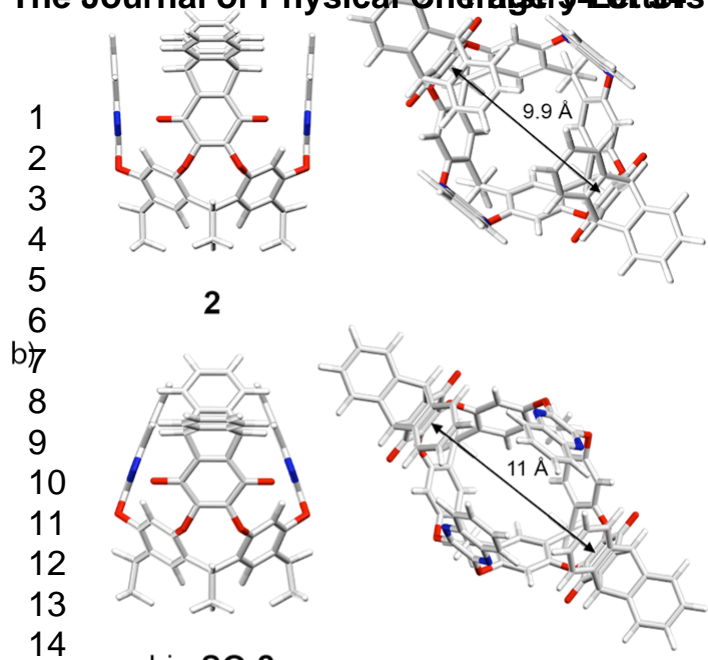

15 bis-SQ-2

c) 16

17

18

19

20

21

22 ACS Paragon Plus

23

$-1=-2$

24

25

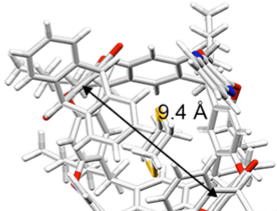

12

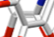

Envirónment 